\title{
PERANCANGAN KOMUNIKASI VISUAL FILM ANIMASI PENDEK “SITIHA DAN SISITI"
}

\author{
Fenny Wijaya $^{1}$; Dyah Gayatri Puspitasari ${ }^{2}$ \\ 1,2 Jurusan Desain Komunikasi Visual, Fakultas Komunikasi dan Multimedia, \\ Bina Nusantara University, Jln. K.H. Syahdan No 9, Kemanggisan, Jakarta Barat 11480 \\ dyah@binus.edu
}

\begin{abstract}
The purpose of this research is to acquire, collect and analyze data needed to realize the design of short animated $3 D$ films with a folklore theme which is presented with a visually appeal to interest spectators, especially children, so the moral message can be conveyed. The research method is to survey directly to the field, namely the cultural center of Indonesia TMII, playground and library. In addition to the literature media such as books, magazines and journals and supported with references from the internet media relating to the topic. Results to be achieved are for the moral message conveyed in this animated folklore film can be received and understood by the audience, especially children. Conclusion at the present time, visual communications media such as movies and television shows are very popular among children. So by using the medium of animated films, children will be more interested and may like local folklore again, since local productions are not of lesser quality than the outside impressions.
\end{abstract}

Keywords: animation, folklore, moral message

\begin{abstract}
ABSTRAK
Tujuan dari penelitian ini untuk memperoleh, mengumpulkan dan menganalisa data-data yang dibutuhkan untuk mewujudkan perancangan film animasi pendek dengan teknik 3 Dimensi yang bertemakan cerita rakyat dengan visual menarik agar dapat menarik minat penonton khususnya anak-anak sehingga pesan moral dapat tersampaikan. Metode penelitian yang digunakan adalah dengan survei langsung ke lapangan, yaitu ke pusat budaya Indonesia TMII, taman bermain dan perpustakaan. Selain itu juga dengan media literatur seperti buku, majalah dan jurnal serta didukung dengan referensi dari media internet yang berhubungan dengan topik. Hasil yang ingin dicapai adalah agar pesan moral yang ingin disampaikan dalam film animasi cerita rakyat ini dapat tersalurkan dan dimengerti oleh penonton, khususnya anak-anak. Simpulannya pada masa sekarang ini, media komunikasi visual seperti film dan tayangan televisi sangat disenangi anak-anak. Maka dengan menggunakan media film animasi, anak-anak akan lebih tertarik dan bisa menyukai cerita rakyat lokal lagi, karena tayangan lokal tidak kalah dari tayangan luar.
\end{abstract}

Kata kunci: animasi, cerita rakyat, pesan moral 


\section{PENDAHULUAN}

Indonesia adalah negeri yang kaya akan kebudayaan dan kesenian lokal, karena keberagaman suku dan adat istiadat membuat Indonesia menjadi negeri yang sangat unik dengan banyak kisah dan latar belakang yang menarik seperti cerita rakyat yang diyakini setiap daerah asalnya. Pada masa sekarang ini, cerita rakyat nusantara kurang diminati oleh anak-anak. Dengan semakin berkembangnya teknologi dan media komunikasi serta pengaruh unsur luar negeri, membuat anak-anak nusantara tidak lagi begitu mengenal dan mencintai budaya serta seni lokal. Banyaknya jenis cerita dari luar negeri, membuat anak-anak beralih untuk meminati jenis cerita tersebut, padahal cerita rakyat nusantara sendiri memiliki banyak sekali manfaat dan orisinalitas budaya yang bisa diperoleh.

Ibu adalah sosok penting dalam perkembangan pribadi anak. Sosok dan peranan ibu dalam cerita rakyat sering diceritakan, serta bagaimana seharusnya anak berbakti kepada orang tuanya. Seperti apapun orang tua, anak harus tetap menghargai dan mencintainya, karena orang tua adalah alasan mengapa mereka bisa hidup di dunia ini. Orang tua merawat, melindungi, membesarkan serta memberikan segala bekal ilmu dan kasih sayang untuk masa depan anak. Cerita rakyat nusantara mengandung ajaran budi pekerti atau pesan moral yang mendidik. Melalui cerita rakyat anak-anak juga bisa mengembangkan sifat-sifat positifnya, misalnya menghormati dan mencintai orang tua apa adanya. Dengan penyampaian yang mudah dan menarik, maka anak-anak tidak akan merasa diperintah tetapi menimbulkan rasa kesadaran dalam diri mereka untuk menjadi anak yang lebih berbakti dan mencintai apa adanya. Cerita rakyat nusantara tentunya memiliki kesan sejarah dan budaya yang kental, sehingga melalui cerita rakyat, anak-anak bisa terajak untuk mencintai dan mengenal budaya dan bangsa sendiri.

Namun dengan segala manfaat yang ada, materi mengenai cerita rakyat nusantara ini tetap saja tidak terlalu tersampaikan ke masyarakat luas, khususnya ke target anak-anak nusantara. Alasan yang biasanya terjadi adalah karena cerita rakyat dengan tampilan tradisional jadi terlihat tidak menarik dan monoton dan juga dianggap tidak cocok dengan perkembangan jaman modern. Selain itu, dengan dampak perkembangan teknologi, anak-anak generasi sekarang daripada membaca buku, lebih berminat pada acara televisi. Kekhawatiran orang tua terhadap acara televisi adalah bagaimana sedikit banyak pengaruhnya terhadap pembentukan dan pengembangan pribadi anak, apabila acara yang ditayangkan tidak baik untuk perkembangan pribadi anak. Namun sesungguhnya dengan bantuan elektronik, cerita rakyat nusantara juga dapat dilestarikan dan disebarkan. Pesan dari cerita rakyat pun bisa tersampaikan dan tetap dinikmati anak-anak misalnya dengan metode penyampaian film animasi cerita rakyat nusantara, yang mana perkembangan animasi di Indonesia juga semakin berkembang dan sedikit banyak mulai menjadi bagian dari anak-anak. Dengan bentuk visual yang menarik maka akan lebih menarik minat anak-anak untuk menkonsumsinya dengan tetap mendapatkan pesan moral cerita rakyat nusantara yang mendidik. Sehingga dengan demikian, kekayaan dan warisan budaya bangsa tetap terjaga dan terpelihara serta konteks lokal bagi anak nusantara pun tercapai dan berkembang.

Berdasarkan pada fakta dan situasi tersebut di dalam kaitannya dengan bidang studi Desain Komunikasi Visual, maka lingkup yang di bahas dibatasi pada hal-hal yang dapat ditangani atau diselesaikan melalui pendekatan DKV, yaitu dengan membuat komunikasi audio visual mengenai cerita pendek animasi yang dibuat dengan $3 D$ Animation dengan tema cerita rakyat nusantara dari Jambi "Sitiha dan Sisiti" yang mengangkat mengenai pentingnya bakti,cinta dan menerima orang tua apa adanya lewat suatu kisah dua orang anak perempuan kembar yang beribukan seekor kucing.

Tujuan pembuatan film animasi pendek cerita rakyat ini adalah untuk menanamkan pesan moral terhadap anak agar berbakti kepada orangtuanya, mencintai serta menghormati mereka apa adanya. Selain itu juga untuk menyampaikan kepada orang tua untuk menerima dan memaafkan kesalahan dan kekhilafan anak mereka dengan tetap mendukung dan membimbing langkah mereka. 
Tujuan untuk menghibur para penonton pun juga dapat tersampaikan dengan pengolahan visual animasi yang baik. Dengan semua tujuan diatas bisa tercapai, maka tujuan untuk melestarikan dan memperkenalkan kembali budaya lokal kepada anak bangsa generasi sekarang pun juga dapat terpenuhi. Bahasan akan mengulas tentang bagaimana merancang komunikasi audio visual dengan film animasi pendek bertema cerita rakyat agar menarik minat penonton sehingga pesan moral serta budaya lokal cerita rakyat tersampaikan dengan tetap memberikan hiburan bagi penonton. Juga bagaimana untuk membuat cerita rakyat hidup kembali di hati anak-anak jaman sekarang.

\section{METODE PENELITIAN}

Metode penelitian yang digunakan adalah berdasarkan studi literature tercetak maupun elektronik dan kunjungan secara langsung ke pusat budaya di Taman Mini Indonesia Indah khususnya anjungan Budaya Jambi. Survei target audience, dan terakhir tahap perancangan visual penciptaan karakter desain tokoh dan suasana lingkungan yang disesuaikan dengan karakter budaya dan kondisi geografis Jambi.

\section{HASIL DAN PEMBAHASAN}

Pesan moral yang disampaikan dari hasil film animasi pendek cerita rakyat ini adalah bagaimana seorang anak harus selalu dapat berbakti, mencintai, menghormati orangtua serta dengan tulus dapat menerima mereka apa adanya. Di sisi lain juga untuk menghimbau para orangtua untuk dapat menerima dan memaafkan kesalahan dan kekhilafan anak dengan tetap mendukung dan membimbing langkah mereka.

Film dirancang dalam bentuk film animasi pendek dengan durasi sekitar 6-7 menit, dimana di dalamnya terdapat pembukaan, inti cerita, klimaks, solusi cerita, akhir cerita bagian credit pembuat film. Film dilengkapi dengan narasi, musik dan efek suara untuk mendukung kelengkapan dari cerita rakyat yang ingin disampaikan berikut pesan moralnya kepada penonton yang khususnya adalah anakanak.

Isi cerita dan judul film diadopsi sesuai dengan cerita aslinya, penambahan skenario hanya dilakukan di scene (adegan) awal yaitu sebagai bentuk cerita dongeng yang diceritakan kembali oleh seorang ibu kepada dua orang anak perempuan kembarnya. Setting ini divisualkan dengan kondisi modern jaman sekarang, dengan tujuan mempermudah penyesuaian awal dan melancarkan alur cerita yang akan disaksikan dan ditangkap oleh penonton anak-anak. Situasi disamakan terlebih dahulu dengan situasi dan kondisi dan kehidupan mereka sehari-hari, yang selanjutnya secara perlahan mengantarkan mereka pada isi cerita yang bersifat dongeng dengan visualisasi lingkungan kehidupan tradisional yang imajinatif.

\section{Perancangan Sinopsis dan Skenario}

Setelah melalui penambahan cerita di adega awal maka selanjutnya sinopsis cerita disusun menjadi sebagai berikut: "Suatu hari, dua anak kembar yang sedang asyik menonton, dilarang oleh ibunya karena sudah waktunya tidur. Kedua anak mengeluh dan membandingkan ibu mereka dengan tetangga. Maka sang ibu pun membacakan dongeng sebelum tidur, agar kedua anak tersebut tidak lagi merasa kesal. Dongeng dimulai dengan pada jaman dahulu kala di sebuah pinggiran desa di Jambi, hiduplah dua anak perempuan bersama dengan ibunya yang seekor kucing. Mereka sangat menyayangi ibunya, hingga suatu ketika ada kejadian yang membuat mereka menjadi malu memiliki 
ibu seekor kucing. Maka mereka melakukan perjalanan untuk mencari ibu baru. Mereka pergi menemui beberapa tokoh untuk dijadikan ibu mereka, seperti matahari, awan, gunung dan tikus. Hingga akhirnya mereka sadar bahwa selama ini ibu mereka adalah yang terhebat dan terbaik dan akhirnya mereka kembali kepada ibu mereka yang setia menyayangi dan menanti kepulangan kedua anak tersebut.”

Selanjutnya dituangkan ke dalam bentuk 8 scene (adegan) skenario.

Babak 1

Scene 1: Int kamar tidur (sekitar pukul 21.00)

a. Kedua anak kembar sedang nonton televisi, kemudian televisi dimatikan oleh ibu mereka karena sudah waktunya mereka tidur.

b. Kedua anak tersebut protes, sang ibu menunjuk jam dan menyuruh mereka berposisi tidur Anak 1: "Bu, Andi tetangga sebelah saja dikasih tidur malam, kita juga donk?" Anak 2: "Iya, betul"

Ibu : "Sudah malam nak, tidur yah"

Anak 1: (menggerutu) "Lebih enak punya ibu tetangga sebelah "

Anak 2: (menggerutu) "Iya"

Ibu : (tersenyum) "Ya sudah, sini ibu bacakan dongeng dulu"

c. Kedua anak rapi dalam posisi siap tidur, dan sang ibu membuka buku cerita rakyat

d. Pengenalan judul, yang berada pada sampul buku cerita rakyat dan perlahan-lahan fade in dari gambar ilustrasi

Scene 2: Ext. halaman rumah di pinggir desa di Jambi (siang hari)

a. Pemandangan suasana alam hutan yang asri dan pinggir pedesaan juga terlihat ada rumah sederhana dan terlihat Sitiha dan Sisiti yang sedang bermain kemudian dipanggil oleh ibu kucing.

Narator: (Dahulu kala di sebuah pinggiran desa di Jambi, hiduplah dua orang anak kembar yang cantik, bernama Sitiha dan Sisiti. Mereka hidup bahagia dengan ibunya, walaupun ibu mereka seekor kucing.)

b. Pergantian siang ke malam kemudian ke siang hari lagi

Narator: (Setiap harinya mereka jalani dengan bahagia.)

Babak 2

Scene 3: Ext. saung depan rumah (siang hari)

a. Kedua anak kembar sedang makan bersama dengan ibunya. Kemudian ada dua orang anak laki-laki melewati rumah mereka dan berhenti sejenak melihat hal tersebut.

Narator: (Hingga pada suatu hari, di siang hari yang cerah ketika Sitiha dan Sisiti sedang asyik makan siang bersama ibu merek, lewatlah dua orang anak laki-laki di depan rumah. Kedua anak itu pun berhenti sejenak karena heran dan bertanya,)

Anak laki-laki 1: "Hei, mengapa kalian makan dan duduk bersama seekor kucing?"

Anak laki-laki 2: “Iya, piringnya juga bagus.”

b. Sitiha, Sisiti dan ibunya melihat ke arah anak-anak itu

Sitiha: "Karena ia adalah ibu kami"

c. Kedua anak laki-laki itu tertawa mendengarnya dan berlalu pergi.

Narator: (Mendengar jawaban Sitiha, kedua anak itu langsung mentertawakan mereka dan berlalu pergi.)

d. Sisiti masuk ke dalam rumah, disusul oleh Sitiha

Narator: (Sitiha dan Sisiti sangat malu ditertawakan karena ibu mereka seekor kucing)

e. Sisiti berbicara sambil berbisik-bisik dengan Sitiha yang sedih.

Narator: (Mereka berdua sangat sedih, hingga akhirnya Sisiti memiliki ide untuk pergi mencari ibu baru yang lebih hebat, agar mereka tidak lagi ditertawakan) 
f. Sitiha dan Sisiti pergi dari rumah

Narator : (Mereka akhirnya pergi dari rumah dan melakukan perjalanan untuk mencari ibu baru yang lebih hebat, tanpa mereka sadari betapa sedih hati ibu mereka yang ditinggalkan)

Scene 4: Int. kamar tidur (malam hari)

Kedua anak kembar terlihat serius mendengarkan dongeng yang ibunya, sambil ibunya melanjutkan cerita

Scene 5: Ext. padang rumput dan perbukitan (siang hari)

a. Sitiha dan Sisiti mulai melakukan perjalanan untuk mencari ibu baru yang akhirnya mereka terpesona akan matahari yang indah.

Narator : (Sitiha dan Sisiti berjalan menyusuri jalan setapak padang rumput dan perbukitan. Kemudian mereka melihat matahari yang bersinar dengan indah. Seketika mereka pun tahu, siapa yang pantas menjadi ibu mereka)

b. Sitiha dan Sisiti menemui matahari

Narator : (Mereka segera berjalan menaiki bukit untuk menemui matahari yang hebat dan indah)

Sitiha : "Matahari, kau sangat hebat dan indah. Sinarmu pun mencerahkan alam ini,"

Sisiti : "Iya matahari, maukah kau menjadi ibu kami?"

Matahari : "Terima kasih atas pujian kalian, tetapi aku tidaklah sekuat itu. Awan lebih hebat dariku, karena ia dapat menghalangi sinarku walau secerah apa pun.”

c. Sitiha dan Sisiti menemui awan

Narator : (Mendengar perkataan matahari, mereka pun pergi mencari awan yang tidak jauh dari matahari dan kemudian memohon hal yang sama)

Sitiha : "Awan, kau terlihat sangat anggun dan lembut. Bahkan matahari yang hebat saja mampu kau kalahkan"

Sisiti : "Iya awan, maukah kau menjadi ibu kami?"

Awan : "Terima kasih, tetapi aku tidaklah sehebat itu. Apabila angin berhembus kencang dan aku terhempas ke gunung, benturan gunung yang keras membuatku pecah menjadi serpihan. Jadi gunung lah yang lebih kuat dan pantas”

d. Sitiha dan Sisiti pun menemui gunung

Narator: (Sitiha dan Sisiti mencari gunung, tidaklah sulit mencari gunung karena ukurannya yang besar dan kokoh. Setelah bertemu dengan gunung, mereka pun mengajukan permohonan yang sama dengan harapan kali ini gunung mau jadi ibu mereka)

Sitiha : "Wahai gunung, kau terlihat sangat kuat dan kokoh, kau pun terlihat indah dari kejauhan.”

Sisiti : "Iya gunung, maukah kau menjadi ibu kami?"

Gunung: "Mengapa kalian berpikir aku sehebat itu? Aku tidak sehebat dugaan kalian"

Sisiti : "Tapi kau sangat kuat."

Gunung: "Aku memang tampak besar dan kuat, tetapi cobalah kalian lihat, tubuhku banyak lubangnya karena ulah tikus. Jadi tikuslah yang lebih kuat dariku."

Sitiha : "Baiklah, terima kasih gunung"

Sisiti : "Terima kasih"

e. Sitiha dan Sisiti pergi meninggalkan gunung

Babak 3

Scene 6: Ext. padang rumput (siang hari)

a. Sitiha dan Sisiti beristirahat sejenak sambil terbayang ibu kucing

Narator: (Setelah berjalan cukup lama, Sitiha dan Sisiti pun beristirahat sejenak di bawah pohon. Mereka sebenarnya merasa rindu dengan ibu kucing. Tetapi mereka tetap merasa harus mencari ibu baru yang lebih hebat agar tidak lagi malu) 
Scene 7: Ext. padang rumput dan perbukitan (siang hari)

a. Sitiha dan Sisiti mencari keberadaan tikus

Narator : (Kemudian mereka pun pergi menemui tikus walaupun mereka tidak tahu pasti dimana rumah tikus)

b. Mereka menyusuri tanah lapang di bawah gunung

Sitiha : "Sisiti, bukankah itu seekor tikus?"

Sisiti : "Iya benar"

c. Sitiha dan Sisiti menghampiri tikus

Narator : (Mereka pun menghampiri tikus yang sedang berada di tanah lapang tersebut dan menanyakan permohonan yang sama kepada tikus)

Sitiha : "Wahai tikus, kau sangat hebat, walau tubuhmu kecil, tetapi gunung yang besar saja tubuhnya berlubang karenamu."

Sisiti : "Iya tikus, maukah kau menjadi ibu kami?"

Tikus : "Hah? Apa kalian tidak salah? Aku mungkin memang bisa melubangi tubuh gunung, tetapi aku tidaklah lebih kuat dari kucing. Kusarankan, kalian lebih baik mencari seekor kucing untuk jadi ibu kalian, karena dialah yang lebih kuat daripada aku."

d. Sitiha dan Sisiti saling bertatapan terkejut

Narator : (Sitiha dan Sisiti sangat kaget mendengar jawaban tikus, mereka tak menyangka bahwa ibu mereka ternyata adalah yang terhebat)

e. Flashback adegan kebersamaan ibu kucing dengan Sitiha dan Sisiti, serta betapa bahagianya mereka dahulu. Ibu kucing yang memperhatikan dan menyayangi mereka

f. Sitiha dan Sisiti tersenyum dan berjalan pulang ke rumah mereka

Narator: (Akhirnya Sitiha dan Sisiti sadar bahwa selama ini apa yang mereka miliki adalah yang terbaik. Meskipun ibu mereka kucing, tetapi ibu mereka adalah yang terhebat)

g. Sitiha dan Sisiti berjalan kerumah dan terlihat ibu kucing sedang menanti mereka (perlahan-lahan fade out menjadi ilustrasi)

Narator : (Mereka juga sadar bahwa ibu mereka tidak dapat tergantikan, dan akhirnya mereka pun hidup lebih saling menyayangi daripada sebelumnya dan bahagia selamanya)]

Scene 8 : Int. kamar tidur (malam hari)

a. Ibu menutup buku cerita dan menatap anak-anaknya

b. Kedua anak kembar juga melihat ke ibu mereka, kemudian memeluk ibu mereka sambil tersenyum

c. Shot suasana kamar tidur dan perlahan menjauh keluar ke jendela kemudian ke langit malam

Narator : (Tamat)

\section{Perancangangan Visual sampai dengan Sinematografi}

Gaya visual yang digunakan adalah gaya kartun sederhana, dengan nuansa warna chromatis dan penerapan tekstur, material yang sederhana. Tipe gerakan yang digunakan adalah gerakan kamera yang perlahan, misalnya zoom in secara perlahan, panning, tilt dan dolly perlahan, agar kesan dramatis yang ingin dicapai dapat tertangkap dan terasa oleh penonton. Perancangan karakter, lingkungan suasana dan properti pendukung dirancang dengan dominasi stilasi bentuk bulat untuk kesan naïf, lucu dan bersahabat. Gaya dan detail ornament pada kostum dan arsitektural mengacu pada budaya Jambi. 


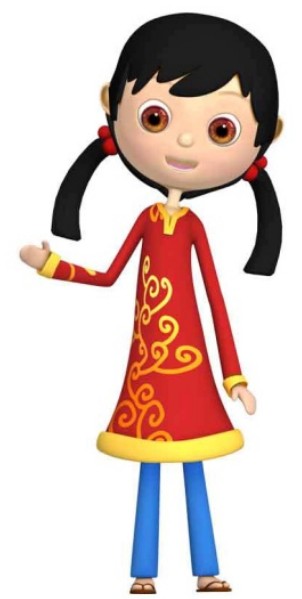

Gambar 1 Sitiha dan Sisiti

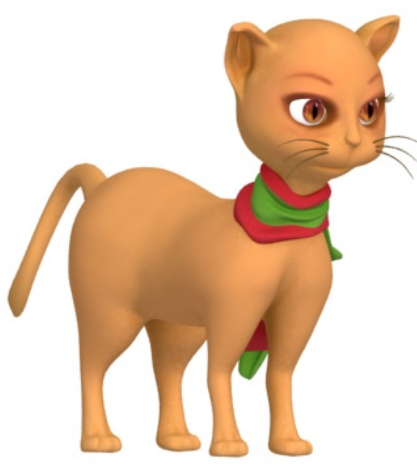

Gambar 2 Ibu Kucing

Pada gambar 1 tampak tokoh karakter Sitiha dan Sisiti yang merupakan tokoh utama dari cerita film animasi pendek ini. Keduanya adalah saudara kembar berumur 10 tahun. Walau kembar mereka mempunyai sedikit perbedaan karakter. Sitiha lebih aktif dan periang dibandingkan dengan Sisiti. Sisiti bersifat lebih pendiam, pasif dan sensitif. Karakter ini coba disampaikan dengan tampilan Sitiha yang berambut panjang diikat dua dan berkostum celana panjang, dan Sisiti yang berambut panjang diiikat satu dengan kostum baju panjang. Rancangan kostum mereka mengadopsi tradisi baju anakanak Jambi dengan aplikasi motif sulur dan ornament geometris yang merupakan salah satu ciri khas motif batik Jambi. Pada gambar 2 tampak tokoh karakter ibu kucing yang divisualisasikan sebagai karakteristik ibu penyayang, sabar dan baik hati. Ciri-ciri fisik mengadopsi tipe jenis kucing pada umumnya yang terdapat di Jambi maupun nusantara. Sentuhan tradisional dihadirkan melalui tampilan aksesoris kostum berupa selendang yang melingkar di leher. Warna selendang diberi warna merah dan hijau yang mengadopsi kecenderungan karakter warna dari tekstil Jambi.
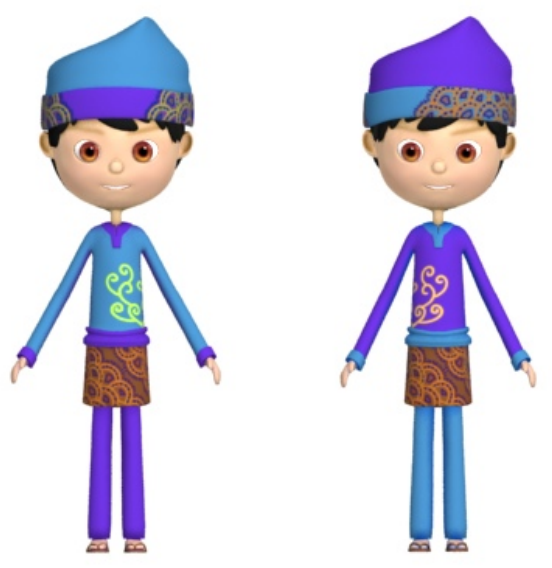

Gambar 3 Anak laki-laki

Pada gambar 3 tampak tokoh karakter dua anak laki-laki yang menggaggu Sitiha dan Sisiti. Dua anak laki-laki ini divisualisikan sebagai anak berumur kurang lebih sama dengan Sitiha dan Sisiti. Rancangan kostum mengadopsi tradisi baju anak-anak laki Jambi lengkap dengan topi khas adat Jambi dengan tambahan sedikit motif sulur batik Jambi dan kain sarung batik yang berwarna cokelat. 


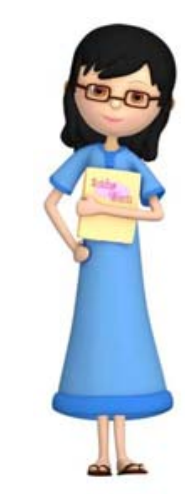

Gambar 4 Ibu Narator

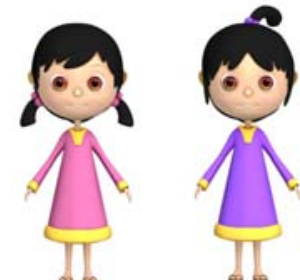

Gambar 5 Anak Perempuan Kembar

Pada gambar 4 tampak tokoh karkter ibu narator. Ibu narator adalah tokoh karakter yang dimunculkan di awal film sebagai narator dari cerita film animasi pendek ini, yaitu sebagai ibu yang membacakan dongeng Sitiha dan Sisiti kepada dua anak perempuan kembarnya. Divisualisasikan sebagaimana ibu di jaman sekarang, dengan karakter penyayang, sabar, tegas dan berpendidikan. Rancangan kostum divisualisasikan dalam bentuk baju santai dan pelengkap sandal jepit, sesuai dengan skenario keberadaan tokoh karakter ibu ini yang ditampilkan sedang berada di rumah bersama kedua anaknya. Pada gambar 5 tampak tokoh karakter dua anak kembar perempuan keci yang ditampilkan sebagai tokoh pembuka yang dimunculkan di awal film. Divisualisasikan sebagai anak kembar umur 5 tahun yang masih manja namun memiliki pemikiran yang kritis. Rancangan kostum berupa baju tidur berwarna merah muda dan biru muda, seperti layaknya baju tidur yang sering dikenakan anak-anak seusianya di jaman sekarang.

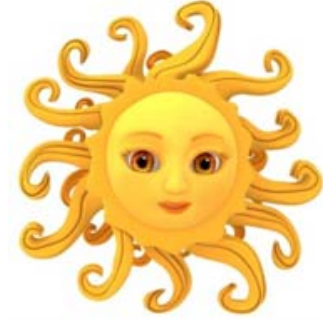

Gambar 6 Matahari

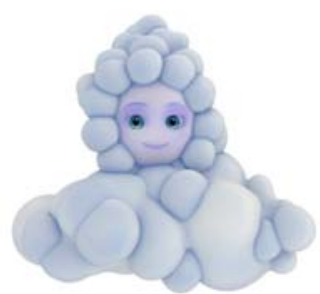

Gambar 7 Awan

Pada gambar 6 tampak tokoh karakter Matahari yang merupakan tokoh pertama yang sempat diminta menjadi ibu oleh Sitiha dan Sisiti. Divisualisasikan sebagai raut wajah yang keibuan, jujur bijaksana,tegas dan berwibawa. Rancangan bentuk pancaran tokoh matahari mengadopsi gaya ukir ornament arsitektural rumah adat Jambi. Pada gambar 7 tampak tokoh karakter awan yang merupakan tokoh kedua yang sempat diminta menjadi ibu oleh Sitiha dan Sisiti. Divisualisasikan dengan raut wajah yang keibuan, lembut, ramah dan bijaksana. Bentuk dirancang berupa kumpulan bulatanbulatan awan kecil yang menyatu.

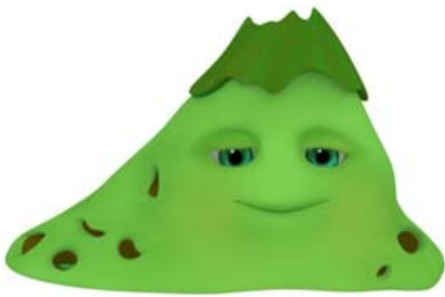

Gambar 8 Gunung

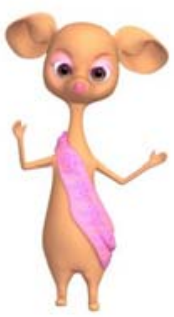

Gambar 9 Tikus 
Pada gambar 8 tampak tokoh karakter gunung yang merupakan tokoh ketiga yang sempat diminta menjadi ibu oleh Sitiha dan Sisiti. Tokoh ini divisualisasikan sebagai bentuk yang besar, dengan raut wajah yang mengantuk, pemalas, gemar tidur, namun baik hati. Rancangan format segitiga ditampilkan dengan sudut-sudut yang membulat tanpa peruncingan untuk lebih menonjokan karakter visual yang bersahabat. Aplikasi warna hijau sebagai gambaran lingkungan alam tropis. Pada gambar 9 tampak tokoh karakter tikus yang merupakan tokoh terakhir yang sempat diminta menjadi ibu oleh Sitiha dan Sisiti. Tokoh ini divisualisasikan sebagai karakteristik wanita pesolek dan ketus. Sentuhan tradisional dihadirkan melalui tampilan aksesoris kostum berupa selendang merah muda yang bermotif sulur Jambi. Perancangan suasana lingkungan mencakup suasana kamar tidur anak kembar, rumah Sitiha dan Sisiti serta ibu kucing, jalan setapak pepohonan dan bukit.

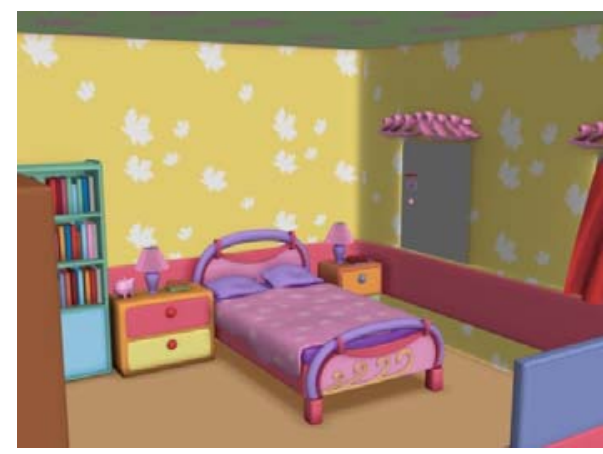

Gambar 10 Kamar Tidur Anak Kembar

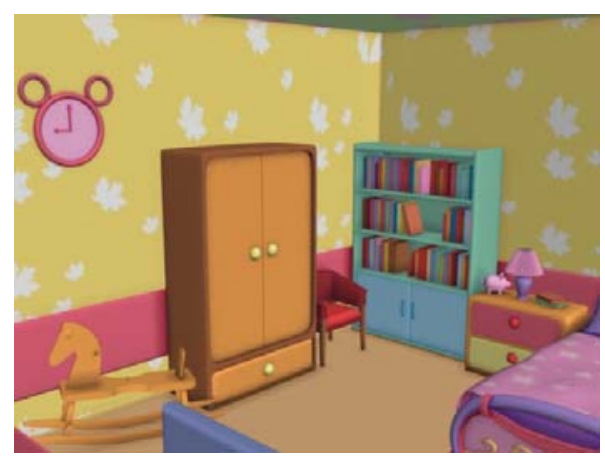

Gambar 11 Perangkat Pendukung Kamar Tidur

Pada gambar 10 dan gambar 11 tampak rancangan suasana kamar tidur anak kembar. Kamar ini adalah lokasi awal sebelum cerita dongeng Sitiha dan Sisiti mulai diceritakan. Kamar tidur divisualisasikan seperti layaknya kamar tidur anak kecil perempuan pada umumnya di masa sekarang. Warna bernuansa pastel, dengan dominasi warna merah muda. Dinding dirancang dengan motif sederhana sesuai dengan karakter kamar tidur anak perempuan. Suasana kamar dilengkapi dengan mainan-mainan, buku cerita dan perangkat pendukung lainnya seperti jam dinding, lampu, dan lainlain.

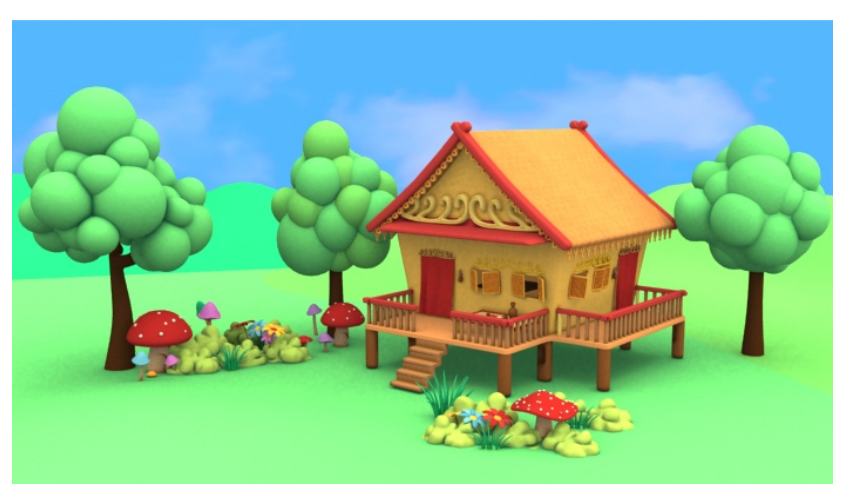

Gambar 12 Rumah Sitiha dan Sisiti serta Ibu Kucing

Pada gambar 12 tampak rancangan suasana lingkungan rumah Sitiha dan Sisiti beserta ibu kucing. Bentuk bangunan rumah divisualisasikan dengan mengadopsi gaya arsitektural rumah adat Jambi yaitu dengan bentuk rumah panggung kayu berikut aplikasi detail ornament ukir dan sulur pada bagian dinding atas dan atap rumah. Dominasi warna coklat pada bangunan rumah dipakai sesuai dengan karakter warna rumah-rumah panggung di Jambi. 


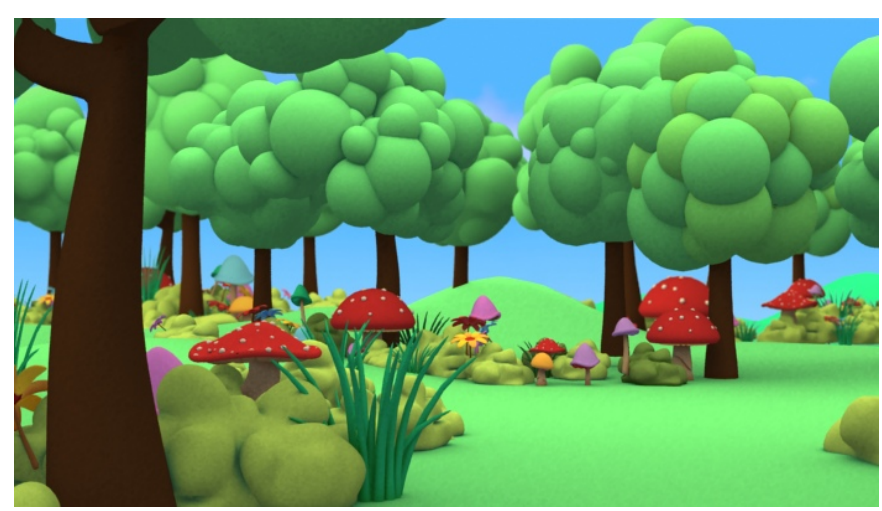

Gambar 13 Jalan Setapak Pohon

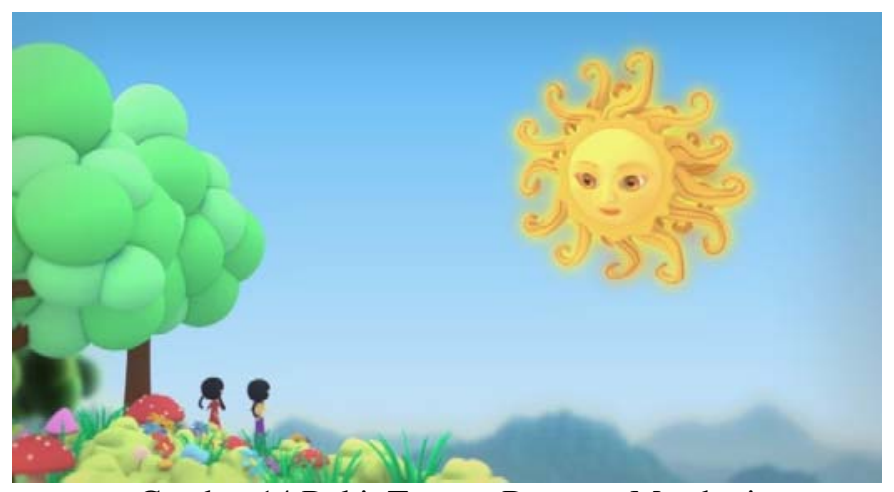

Gambar 14 Bukit Tempat Bertemu Matahari

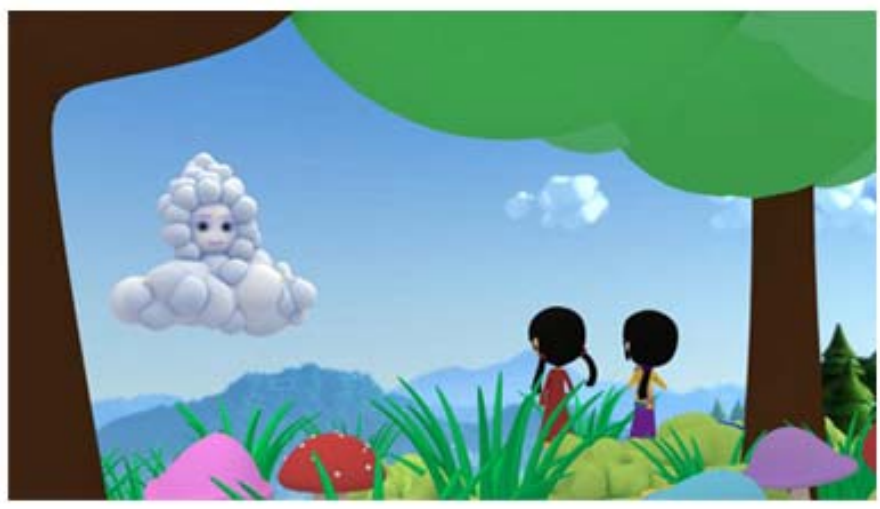

Gambar 15 Bukit Tempat Bertemu Awan

Pada Gambar 13, Gambar 14, dan Gambar 15, tampak rancangan suasana lingkungan jalan setapak pohon dan bukit tempat Sitiha dan Sisiti bertemu matahari dan awan. Suasana lingkungan alam divisualisasikan dengan karakter lingkungan alam tropis yang subur dan cerah, disertai dengan modifikasi figur-figur visual yang imajinatif dan dramatis untuk memperkuat nuansa alam dunia dongeng.

Sinematografi yang akan digunakan dalam film animasi pendek "Sitiha dan Sisiti” adalah teknik pengambilan gambar yang biasa digunakan pada umumnya. Karena film animasi pendek ini lebih berupa genre drama, maka tidak akan menggunakan teknik pengambilan gambar kamera yang ekstrim atau banyak bergerak. 

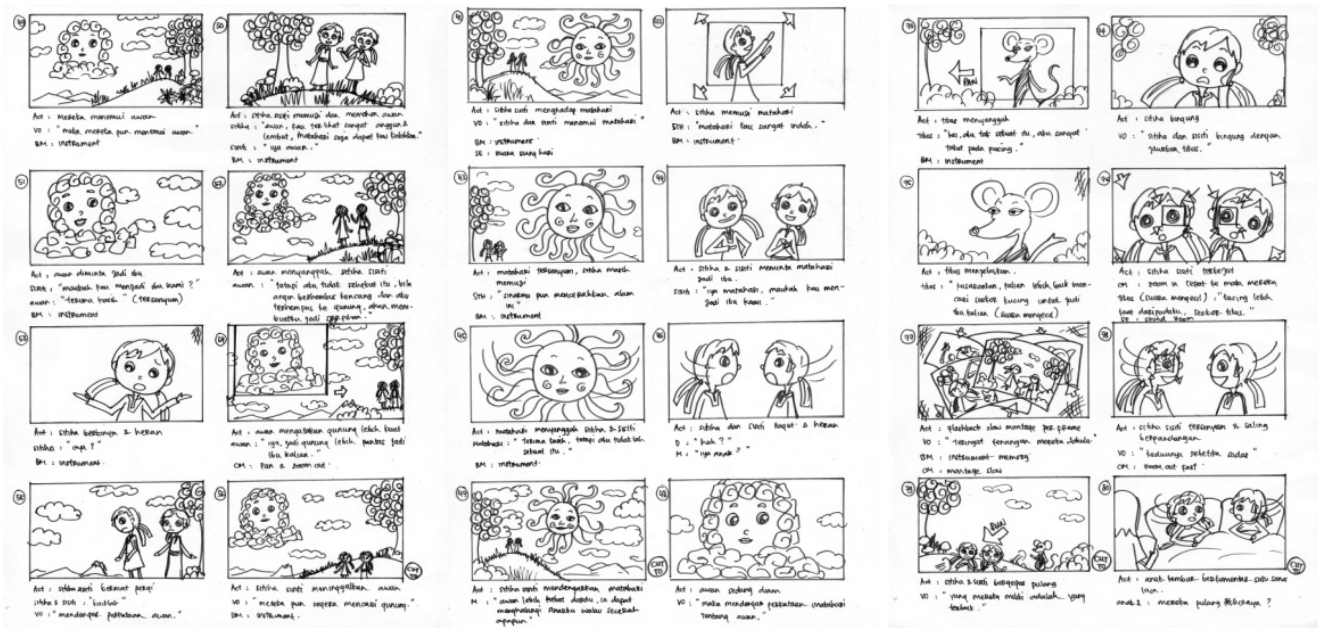

Gambar 16 Sketsa Storyboard

Pada gambar 16 dapat dilihat cuplikan rangkaian sketsa storyboard (jalan cerita) film animasi pendek "Sitiha dan Sisiti”. Thumbnails (sketsa kasar) ini dirancang dan dirangkai sesuai dengan alur adegan yang telah ditetapkan di tahap perancangan tiap babak adegan skenario, untuk selanjutnya dijadikan acuan perancangan pada proses pengambilan gambar film.

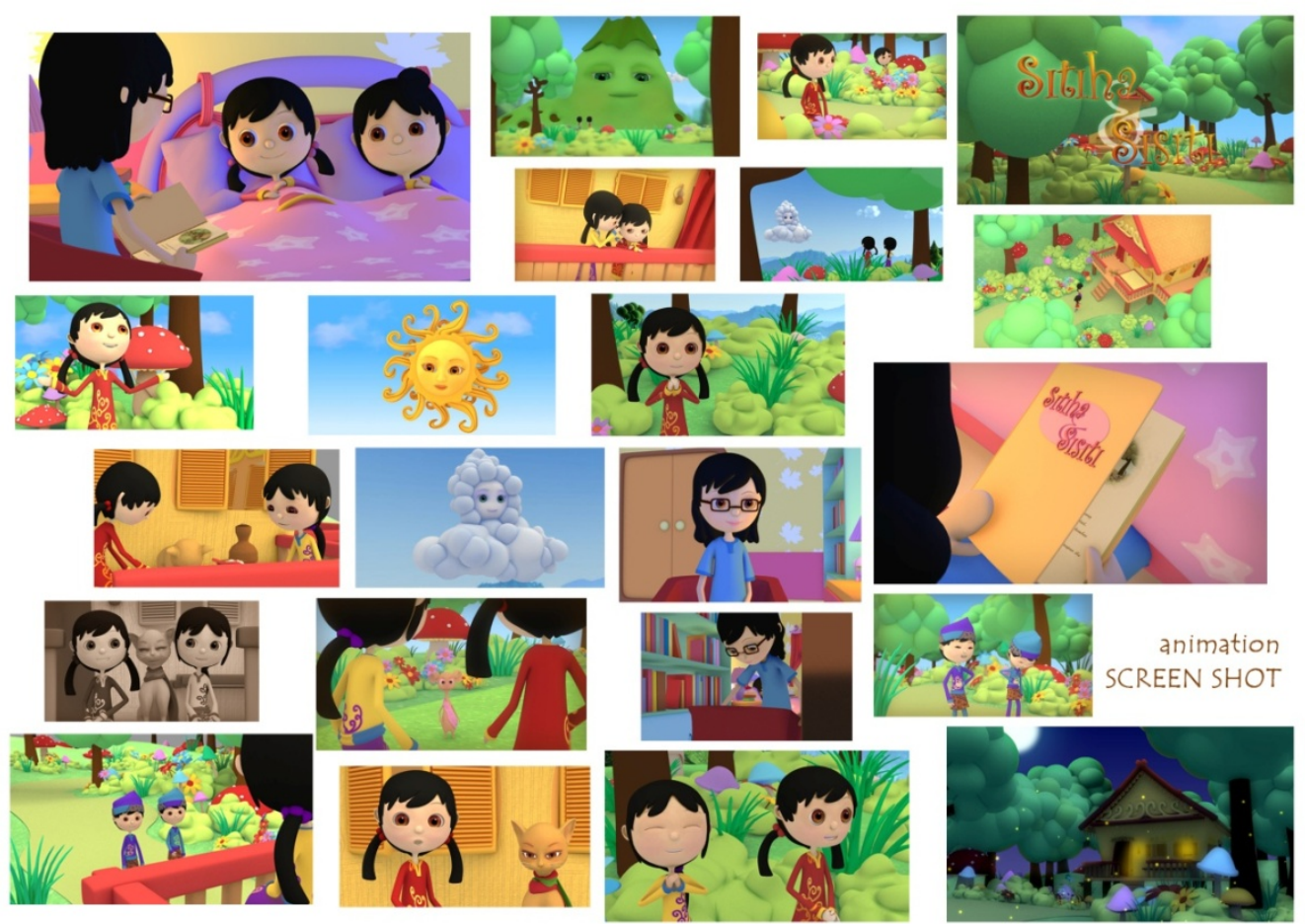

Gambar 17 Screenshot Film Animasi Pendek "Sitiha dan Sisiti”

Pada gambar 17 dapat dilihat screenshot (cuplikan gambar adegan) dari film animasi pendek "Sitiha dan Sisiti”, yang mengacu dari rancangan alur storyboard yang telah ditetapkan. 


\section{SIMPULAN}

Kesimpulan yang dapat diperoleh adalah bahwa dalam peranannya, komunikasi menggunakan media audio visual sangatlah berguna dan efektif untuk menjangkau masyarakat. Pengembangan audio visual dengan kemasan dan keseluruhan yang menarik akan lebih membangkitkan minat dari target audience yang dalam hal ini khususnya adalah anak-anak, sehingga pesan moral yang ingin disampaikan pun dapat diterima dengan lebih mudah oleh anak-anak. Sehingga dengan adanya pembuatan film pendek animasi dengan tema cerita rakyat ini akan membantu perkembangan animasi lokal di Indonesia. Maka dengan tema sederhana, lokal dan mencerminkan serta memperkenalkan budaya Indonesia seperti cerita rakyat, apabila dibuat dengan menarik seperti dengan teknologi 3D, maka diharapkan masyarakat dapat memetik hal positif dari film animasi pendek cerita rakyat ini. Dengan adanya film animasi pendek "Sitiha dan Sisiti" ini, disarankan agar perkembangan animasi dengan tema lokal dan berbudaya terus dikembangkan, agar generasi muda pun akan terlatih untuk mencintai produk lokal dan lebih baik lagi apabila turut berusaha untuk mengembangkannya.

\section{DAFTAR PUSTAKA}

Christantiowati. (2009). Batik Jambi. National Geographic Traveler, Vol 1, pp54.

Johnston, O., \& Thomas, F. (1995). The Illusion of Life: Disney Animation. USA: Barnes and Noble.

Maestri, G. (1999). Digital Character Animation 2. Indianapolis, USA: New Riders Publishing.

Purbasari, M. (2001). Komunikasi Warna. Jurnal Aksen, Vol 2, pp34

Sambangsari, S. (2009). Kumpulan Cerita Rakyat Nusantara. Jakarta Selatan: PT. Wahyu Media.

Soedjijono. (2007). Poetika Naratif: Teori Prosa Naratif Berdasarkan Studi Konvensi Kesastraan Cerita Rakyat Daerah di Indonesia. Bahasa dan Seni, Vol 1, pp28.

Sujiono, Y. N. (2009). Konsep Dasar Pendidikan Anak Usia Dini. Jakarta: PT. Indeks.

Tasai, A. (1990). Sitiha dan Sisiti. Cerita Rakyat dari Jambi. Jakarta: PT. Gramedia Widiasarana Indonesia.

Utomo, B. B. \& rekan. (2009). Treasures of Sumatra. Jakarta: Museum Nasional.

Wagner, F. A. (1988). Art of Indonesia. Singapore: Graham Brash (Pte) Ltd.

White, H. (1994). How to Produce Effective TV Commercials. (3rd ed.). Illinois, USA: NTC Publishing Group.

Yudoseputro, W. (1994). Pengantar Wawasan Seni Budaya. Jakarta: PT Lansam Dwitunggal Lestari. 